\title{
OPEN Effects of home quarantine during COVID-19 lockdown on physical activity and dietary habits of adults in Saudi Arabia
}

\begin{abstract}
Hanan Alfawaz ${ }^{1,2}$, Osama E. Amer ${ }^{1}$, Abdulaziz A. Aljumah ${ }^{3}$, Dara A. Aldisi ${ }^{4}$, Mushira A. Enani ${ }^{5}$, Naji J. Aljohani ${ }^{1,6}$, Naif H. Alotaibi ${ }^{7}$, Naemah Alshingetti ${ }^{8}$, Suliman Y. Alomar ${ }^{9}$, Malak Nawaz Khan Khattak ${ }^{1}$, Shaun Sabico ${ }^{1}$ \& Nasser M. Al-Daghri ${ }^{1 凶}$

Public health endorsements during the present COVID-19 pandemic has led the governments of largely affected countries to imply policies that restrict social mobility to slow COVID-19 spread. The study aimed to explore the effects of COVID-19 home quarantine on lifestyle and health behavior of Saudi residents. An online survey in Saudi Arabia was launched from May 11 to June 6, 2020. The survey was designed by multidisciplinary scientists and academics uploaded and shared through the Google platform in Arabic and English languages. Questions presented related to responses "before" and "during" COVID-19 home quarantine. A total of 1965 respondents participated and were included in the analysis [921 (47.0\%) males and 1044 (53.0\%) females]. Non-Saudis were more likely to increase their physical activity during quarantine [odds ratio (95\% confidence interval 1.41 (1.11-1.79); $p<0.005]$. Prevalence of participants walking daily for more than 4 times per week significantly decreased during pandemic (before vs during, $30.5 \%$ vs $29.1 \%$ ) which was in parallel to the significant increase in the prevalence of participants who did not perform daily walking during the quarantine ( $21 \%$ vs $22.9 \% ; p<0.001$ ). The prevalence of participants who often consume snacks between meals increased during quarantine $(27.4 \%$ vs $29.4 \%, p<0.001)$, while the prevalence of participants who never consumed fresh fruits and vegetables significantly increased during home quarantine $(2.4 \%$ vs $3.7 \% ; p=0.019$ ). The lockdown imposed in Saudi Arabia modestly but significantly impacted physical activity and dietary behaviors of several citizens and residents in an unhealthy way. Interventions to alleviate these acute adverse lifestyle behaviors during pandemic should be formulated.
\end{abstract}

The present pandemic of COVID-19 has caused governments of largely affected countries to force harsh lockdown precautionary rules on their citizens. These included working from home, closing shops, schools, restaurants and any non-essential service or business to slow down the spread of the outbreak and prevent health care system collapse. These quarantine rules resulted in unhealthy behaviors which adversely affected the general population health ${ }^{1,2}$. Furthermore, restrictions in physical activity was due to closed sport centers/gyms and limited social mobility ${ }^{3}$. These limitations may aggravate sedentary lifestyle, an unhealthy habit highly prevalent in developed nations, including Saudi Arabia ${ }^{4}$. In fact, before the pandemic, being sedentary was already deemed a major public health problem, with more than a quarter of all adults not meeting the required physical activity levels for maintaining good health ${ }^{5}$. During the pandemic however, a recently released data for physical activity by Fitbit, Inc., indicated that the average step counts of more than 30 million users and showed a significant

\footnotetext{
${ }^{1}$ Chair for Biomarkers of Chronic Diseases, Biochemistry Department, College of Science, King Saud University, PO Box 2455, Riyadh 11451, Saudi Arabia. ${ }^{2}$ College of Food Science and Agriculture, Department of Food Science and Nutrition, King Saud University, Riyadh 11495, Saudi Arabia. ${ }^{3}$ College of Medicine Medical Student, Almaarefa University, Riyadh 11597, Saudi Arabia. ${ }^{4}$ Department of Community Health Sciences, College of Applied Medical Sciences, King Saud University, Riyadh 11451, Saudi Arabia. ${ }^{5}$ Medical Specialties Department, King Fahad Medical City, Riyadh 59046, Saudi Arabia. ${ }^{6}$ Obesity, Endocrine and Metabolism Center, Department of Medicine, King Fahad Medical City, Riyadh, Saudi Arabia. ${ }^{7}$ Department of Medicine, College of Medicine, King Saud University, Riyadh, Saudi Arabia. ${ }^{8}$ Obstetrics and Gynaecology Department, King Salman Bin Abdulaziz Hospital, Riyadh 11564, Saudi Arabia. ${ }^{9}$ Doping Research Chair, Department of Zoology, College of Science, King Saud University, Riyadh 11495, Saudi Arabia. ${ }^{\boxplus}$ email: ndaghri@ksu.edu.sa
} 


\begin{tabular}{|l|l|l|l|l|}
\hline Event & Dates & Curfew hours & Exceptions & \multirow{2}{*}{ (\%) } \\
\hline Suspension of non-essential work & Mar 15 & & None & \\
\cline { 1 - 4 } Nationwide curfew & Mar 23-Apr 5 & 6AM-7PM & Makkah/Madinah & \\
\cline { 1 - 2 } Enhanced curfew & Apr 6-25 & 6AM-3PM & None & \\
\hline Ramadan $^{\mathrm{a}}$ & Apr 26-May 22 & 9AM-5PM & Makkah & \multirow{2}{*}{$1476(75.1)$} \\
\hline Eid Al Fitr $^{\mathrm{a}}$ & May 23-27 & 24 h & None & \multirow{2}{*}{$422(21.5)$} \\
\hline Phase 1 partial easing & May 28-30 & 6AM-3PM & Makkah & $56(2.8)$ \\
\hline Phase 2 partial easing & May 31-Jun 20 & 6AM-6PM & Makkah & $11(0.6)$ \\
\hline
\end{tabular}

Table 1. Timeline of Events. ${ }^{a}$ Denotes events that unfolded during the study period (May 11-June 6, 2020).

decline in step count which varied across nations, ranging from 7 to $38 \%$ decrease during the week ending March 22,2020 , as compared with the same period last year ${ }^{6}$. This observation suggested that isolation may provoke an extensive reduction in physical activity levels as observed in other confined situations like incarceration and space travel ${ }^{7,8}$. Given that a chronic sedentary lifestyle is detrimental for health ${ }^{9}$, light weight activities come into play, as decreasing sitting times is similarly important as increasing exercising periods ${ }^{10}$.

Other consequences of prolonged quarantine include altered nutritional intake, e.g., overeating ${ }^{11,12}$. During quarantine, our diet is altered to include foods with a long shelf-life, again, due to limited access for outdoor food purchases ${ }^{11}$. Additionally, many people typically respond to chronic stressful conditions by seeking out foods that are dense in energy ${ }^{13-16}$. Torres and colleagues observed that people tend to alleviate the lockdown-related stress by having a higher than normal consumption of less nutritious but comforting foods (e.g., hamburgers, snacks, chocolate, and carbonated beverages) in an attempt to feel better (stress-related eating) ${ }^{17}$. Furthermore, isolation during quarantine harbors lack of emotional support from relatives and friends which is predictive of stress-driven eating and drinking behaviors ${ }^{18,19}$.

Most of the COVID-19 studies in Saudi Arabia have focused on pre-existing conditions with final outcomes $^{20,21}$, as well as dietary changes and mental health ${ }^{22,23}$. Given that lockdowns primarily promote a more sedentary and passive lifestyle, the present study aimed to determine the extent of altered lifestyle behavior changes during this period through a structured online survey distributed to residents of Saudi Arabia.

\section{Methods}

Study design and participants. This cross-sectional survey was conducted from May 11 to June 6, 2020, corresponding to 2 weeks during and after the holy month of Ramadan (April 23-May 23, 2020), using an online electronic survey (supplementary file 1). Within this timeframe, confirmed Covid-19 cases in Saudi Arabia increased from 41,014 to 98,869 (John Hopkins Corona Center; https://coronavirus.jhu.edu/) ${ }^{24}$. Table 1 shows the timeline of events with respect to restrictions imposed in Saudi Arabia and the questionnaire respondents for each event. Majority of the respondents answered the questionnaire during Ramadan (75.1\%). All adult Saudi citizens and residents (non-Saudis) 18 years old and above with access to internet were deemed eligible to voluntarily participate in the survey. All participants were asked for their email addresses for verification purposes only and to ensure that each participant completed the survey only once. The study design and protocol were approved by the Ethics Committee for Scientific Research and Post Graduate Studies at the College of Science, King Saud University, Saudi Arabia (reference\# KSU-HE-20-246). Informed consent was obtained from all respondents. All methods were carried out in accordance with relevant guidelines and regulations.

Questionnaire. The questionnaire included a cover letter in Arabic and English. It consisted of demographic and social information, general awareness about the pandemic and statements in Likert scale format to determine changes in behavioral lifestyle, dietary habits, physical activity, and mental wellness among others. Experts in the related field reviewed the questionnaire and several revisions were made to strengthen the reliability and validity of the questionnaire as well as enhance scientific value of the data to be collected. A pilot study $(n=75$ participants) was performed to confirm reliability and validity of the questionnaire and obtained Cronbach's $\alpha$, which was noted to be excellent (overall $84 \%$, demographics $88 \%$, physical activity $81 \%$ and dietary habits $91 \%$ ). After completion, the questionnaire was cascaded to different social media outlets throughout Saudi Arabia.

Sample size calculation. Sample size calculation was done using Raosoft online to specify the number of respondents needed with an error margin to meet the desired confidence level. To obtain a confidence level of $95 \%$ and a $2.2 \%$ margin of error, a minimum sample size of 1946 would enable us to achieve the study objectives.

Data analysis. Analysis was done using SPSS version 16.5 (Chicago, IL, USA). Continuous variables were presented as mean \pm standard deviation while categorical variables were presented as frequencies $(\mathrm{N})$ and percentages (\%). Chi-Square test was used to determine differences between categorical variables of interest. Independent T-test was used to determine differences between normal continuous variables and Mann-Whitney U-test for non-normal continuous variables. Cochran's Q test was used to assess the main effects of groups over time before and during the pandemic. Post-hoc comparisons between scales was done using McNemar's test. Multinomial logistic regression analysis was performed for physical activities change for independent predic- 


\begin{tabular}{|c|c|c|c|c|}
\hline Parameters & All & Males & Females & $p$ value \\
\hline $\mathrm{N}(\%)$ & 1965 & $921(46.9)$ & $1044(53.1)$ & \\
\hline $\operatorname{Age}^{\star}($ year $)(\min -\max )$ & $35.2 \pm 13.1(15-75)$ & $35.2 \pm 13.1(16-72)$ & $35.1 \pm 12.9(15-70)$ & 0.80 \\
\hline $15-25$ year & $609(31.0)$ & $292(31.7)$ & $317(30.4)$ & \multirow{4}{*}{0.49} \\
\hline $26-35$ year & $516(26.3)$ & $231(25.1)$ & $285(27.3)$ & \\
\hline $36-45$ year & $411(20.9)$ & $187(20.3)$ & $224(21.5)$ & \\
\hline$>45$ year & $429(21.8)$ & $211(22.9)$ & $218(20.9)$ & \\
\hline \multicolumn{5}{|l|}{ Marital status (\%) } \\
\hline Single & $860(43.8)$ & $355(38.5)$ & $509(48.8)$ & \multirow{4}{*}{$<0.001$} \\
\hline Married & $1040(52.9)$ & $566(61.6)$ & $474(45.4)$ & \\
\hline Divorce & $49(2.5)$ & $0(0.0)$ & $49(4.7)$ & \\
\hline Widow/widower & $12(0.6)$ & $0(0.0)$ & $12(1.1)$ & \\
\hline \multicolumn{5}{|l|}{ Nationality (\%) } \\
\hline Saudi & $1632(83.1)$ & $777(84.4)$ & 855 (81.9) & \multirow{3}{*}{0.15} \\
\hline Non-Saudi & $333(16.9)$ & $144(15.6)$ & $189(18.1)$ & \\
\hline \multicolumn{4}{|l|}{ Education (\%) } & \\
\hline High school & $165(8.4)$ & $75(8.1)$ & $90(8.6)$ & \multirow{4}{*}{0.36} \\
\hline Bachelor & $1158(58.9)$ & $556(60.4)$ & $602(57.7)$ & \\
\hline Master & $368(18.7)$ & $158(17.2)$ & $210(20.1)$ & \\
\hline PHD & $274(13.9)$ & $132(14.3)$ & $142(13.6)$ & \\
\hline \multicolumn{5}{|c|}{ Family monthly income (SAR) (\%) } \\
\hline$<5000$ & $687(35.0)$ & $338(36.7)$ & $349(33.4)$ & \multirow{4}{*}{0.42} \\
\hline $5000-7000$ & $200(10.2)$ & $93(10.1)$ & $107(10.2)$ & \\
\hline $8000-16,000$ & $580(29.5)$ & $258(28.0)$ & $322(30.8)$ & \\
\hline$>16,000$ & $498(25.3)$ & $232(25.2)$ & $266(25.5)$ & \\
\hline \multicolumn{5}{|l|}{ Employment status (\%) } \\
\hline Employed & $1100(56.0)$ & $495(53.7)$ & $605(58.0)$ & \multirow{5}{*}{0.30} \\
\hline Unemployed & $217(11.0)$ & $113(12.3)$ & $104(10.0)$ & \\
\hline Student & $597(30.4)$ & $286(31.1)$ & $311(29.8)$ & \\
\hline Own business & $2(0.1)$ & $1(0.1)$ & $1(0.1)$ & \\
\hline Farmer & $49(2.5)$ & $26(2.8)$ & $23(2.2)$ & \\
\hline \multicolumn{5}{|l|}{ Family members (\%) } \\
\hline 02-Apr & $545(27.7)$ & $261(28.3)$ & $284(27.2)$ & \multirow{4}{*}{0.82} \\
\hline 04-Jun & $700(35.6)$ & 319 (34.6) & $381(36.5)$ & \\
\hline$>6$ & 587 (29.9) & $276(30.0)$ & $311(29.8)$ & \\
\hline Single & $133(6.8)$ & $65(7.1)$ & $68(6.5)$ & \\
\hline
\end{tabular}

Table 2. Demographic characteristics of participants. Data presented as n (\%); ${ }^{\star}$ denotes data presented as mean \pm standard deviation. $p$ value significant at $<0.05$.

tors. Assumptions on independence within observations, uncorrelated errors and consistency in coding were confirmed prior to reliability analysis (Cronbach $\alpha>0.7$ ). $p$ value was considered significant at $p<0.05$.

\section{Results}

Sample description. This cross-sectional study included a total of 1,965 respondents [males, $\mathrm{n}=921$ (46.9\%) and females, $\mathrm{n}=1044$ (53.1\%) participants], all of whom completed the entire questionnaire. Table 2 shows the demographic characteristics of the participants.

Table 3 shows physical activity information from all responses before and during home quarantine. Over-all significant differences were observed in between group comparisons over time for physical activity in terms of walking, home physical activities with weights and swimming ( $p$ values $<0.001)$. In the daily walking physical activities, the percentage of participants walking daily for more than 4 times per week significantly decreased during pandemic (before vs during, $30.5 \%$ vs $29.1 \%$; $p<0.05$ ) which was in parallel to the significant increase in the percentage of participants who did not perform daily walking during the quarantine $(21 \% \mathrm{vs} 23.6 \% ; p<0.001)$. Similarly, the percentage of participants who never performed home physical activities with weights before the quarantine significantly increased during the quarantine $(42.8 \%$ vs $44.6 \% ; p<0.001)$. In contrast, there was a significant percentage of participants who increased their frequency by 3-4 times per week in swimming during the quarantine ( $3 \%$ vs $4.6 \% ; p<0.001$ ).

Table 4 demonstrates the unadjusted odds ratios (ORs) with confidence intervals (95\% CI) of factors affecting physical activity. In general, physical activity was highest among: Non-Saudis [OR 1.41 (1.11-1.79); $p=0.005$ ], high income $[1.45(1.05-1.99) ;<0.05]$ and middle age $[1.57(1.22-2.01) ; p=0.001]$. Physical activity was lowest 


\begin{tabular}{|c|c|c|c|c|c|c|c|c|c|}
\hline \multirow[b]{3}{*}{ Physical activity } & \multicolumn{8}{|c|}{ Days per week [n (\%)] } & \multirow[b]{3}{*}{$p$ value } \\
\hline & \multicolumn{4}{|c|}{ Before } & \multicolumn{4}{|l|}{ During } & \\
\hline & Never & $1-2$ & $3-4$ & $>4$ & Never & $1-2$ & $3-4$ & $>4$ & \\
\hline Daily walking & $413(21.0)$ & $463(23.6)$ & $489(24.9)$ & $600(30.5)$ & $464(23.6)^{* *}$ & $450(22.9)$ & $479(24.4)$ & $572(29.1)^{\star}$ & $<0.001$ \\
\hline $\begin{array}{l}\text { Home physical } \\
\text { activities with } \\
\text { weights }\end{array}$ & $842(42.8)$ & $374(19.0)$ & $354(18.0)$ & $395(20.1)$ & $877(44.6)^{* *}$ & $369(18.8)$ & $336(17.1)$ & $383(19.5)$ & $<0.001$ \\
\hline Swimming & \begin{tabular}{|l|}
$1737(88.4)$ \\
\end{tabular} & \begin{tabular}{|l|}
$128(6.5)$ \\
\end{tabular} & $58(3.0)$ & $42(2.1)$ & $1693(86.2)^{* *}$ & $132(6.7)$ & $90(4.6)^{* *}$ & $50(2.5)$ & $<0.001$ \\
\hline
\end{tabular}

Table 3. Responses to the physical activity questionnaire recorded before and during home quarantine. Data presented $\mathrm{n}(\%){ }^{*}$ and ${ }^{*}$ represented $p$ value significant at $<0.05$ and 0.01 level using Cochran's $\mathrm{Q}$ test and McNemar's test.

\begin{tabular}{|c|c|c|}
\hline \multirow[b]{2}{*}{ Categories } & \multirow{2}{*}{\begin{tabular}{|l|} 
All \\
Crude OR $(95 \% \mathrm{CI})$ \\
\end{tabular}} & \multirow[b]{2}{*}{$p$ value } \\
\hline & & \\
\hline \multicolumn{3}{|l|}{ Marital status } \\
\hline Single & 1 & 0.22 \\
\hline Married & $1.12(0.93-1.34)$ & 0.80 \\
\hline Divorce & $0.93(0.52-1.65)$ & \multirow{2}{*}{0.44} \\
\hline Widow & $0.64(0.20-2.02)$ & \\
\hline \multicolumn{3}{|l|}{ Nationality } \\
\hline Saudi & 1 & \multirow{2}{*}{0.005} \\
\hline Non-Saudi & $1.41(1.11-1.79)$ & \\
\hline \multicolumn{3}{|l|}{ Education } \\
\hline High school & 1 & 0.21 \\
\hline Bachelor & $0.81(0.58-1.13)$ & 0.004 \\
\hline Master & $0.58(0.40-0.84)$ & \multirow{2}{*}{0.48} \\
\hline PHD & $1.15(0.78-1.71)$ & \\
\hline \multicolumn{3}{|c|}{ Family monthly income } \\
\hline$<5000$ & 1 & 0.02 \\
\hline $5000-7000$ & $1.45(1.05-1.99)$ & 0.13 \\
\hline $8000-16,000$ & $1.19(0.95-1.48)$ & \multirow{2}{*}{0.02} \\
\hline$>16,000$ & $1.31(1.04-1.65)$ & \\
\hline \multicolumn{3}{|c|}{ Employment status } \\
\hline Employed & 1 & 0.91 \\
\hline Unemployed & $0.98(0.73-1.32)$ & 0.06 \\
\hline Student & $0.82(0.67-1.01)$ & \multirow{2}{*}{0.63} \\
\hline Own business & $1.15(0.64-2.06)$ & \\
\hline \multicolumn{3}{|c|}{ Family members } \\
\hline 02-Apr & 1 & 0.77 \\
\hline 04-Jun & $1.03(0.83-1.29)$ & 0.83 \\
\hline$>6$ & $0.97(0.77-1.23)$ & \multirow{2}{*}{0.61} \\
\hline Single & $0.91(0.62-1.33)$ & \\
\hline \multicolumn{3}{|l|}{ Age } \\
\hline $15-29$ year & 1 & 0.71 \\
\hline $30-44$ year & $1.04(0.85-1.28)$ & $<0.001$ \\
\hline 45-59 year & $1.57(1.22-2.01)$ & \multirow{2}{*}{0.35} \\
\hline$>60$ year & $1.21(0.81-1.79)$ & \\
\hline
\end{tabular}

Table 4. Factors affecting physical activity. Data presented odd ratio $(95 \% \mathrm{CI})$. $p$ value $<0.05,0.01$ consider significant.

among respondents with master's degree [0.58 $(0.40-0.84) ; p=0.004]$. Non-Saudis were more likely to increase their physical activity during quarantine.

Majority of the respondents didn't do group physical activity at home with their families (84.7\%), and most didn't try to improve their physical activity habits during the quarantine (not shown in tables). 


\begin{tabular}{|c|c|c|c|c|c|c|c|c|c|c|c|}
\hline \multirow[b]{2}{*}{ Dietary information } & \multicolumn{5}{|l|}{ Before } & \multicolumn{5}{|l|}{ During } & \multirow[b]{2}{*}{$p$ value } \\
\hline & Never & Hardly & Sometime & Often & Always & Never & Hardly & Sometime & Often & Always & \\
\hline Interest in healthy diet & $43(2.2)$ & $203(10.3)$ & $312(15.9)$ & $680(34.6)$ & $727(37.0)$ & $61(3.1)^{*}$ & $169(8.6)^{*}$ & $332(16.9)$ & $754(38.4)^{* *}$ & $649(33.0)^{* *}$ & $<0.001$ \\
\hline \multicolumn{12}{|l|}{ Consumption of... } \\
\hline Fast food & $30(1.5)$ & $119(6.1)$ & $263(13.4)$ & $452(23.0)$ & $1101(56.0)$ & $72(3.7)^{* *}$ & $110(5.6)$ & $265(13.5)$ & $478(24.3)$ & $1040(52.9)^{* *}$ & $<0.001$ \\
\hline Coffee from coffee shops & $56(2.8)$ & $128(6.5)$ & $301(15.3)$ & $702(35.7)$ & $778(39.6)$ & $65(3.3)$ & $132(6.7)$ & $318(16.2)$ & $750(38.2)^{*}$ & $700(35.6)^{\star *}$ & $<0.001$ \\
\hline Snacks between meals & $181(9.2)$ & $603(30.7)$ & $395(20.1)$ & $539(27.4)$ & $247(12.6)$ & $188(9.6)$ & $535(27.2)$ & $432(22.0)^{* *}$ & $578(29.4)$ & $232(11.8)$ & 0.007 \\
\hline Homemade food & $238(12.1)$ & $644(32.8)$ & $423(21.5)$ & $395(20.1)$ & $265(13.5)$ & $329(16.7)^{* *}$ & $612(31.1)$ & $403(20.5)$ & $378(19.2)$ & $243(12.4)^{*}$ & $<0.001$ \\
\hline $\begin{array}{l}\text { Fresh fruits and veg- } \\
\text { etables }\end{array}$ & $47(2.4)$ & $231(11.8)$ & $390(19.8)$ & 777 (39.5) & $520(26.5)$ & $73(3.7)^{\star \star}$ & $223(11.3)$ & $391(19.9)$ & $784(39.9)$ & $494(25.1)$ & 0.019 \\
\hline
\end{tabular}

Table 5. Dietary information in all subjects. Data presented $\mathrm{n}(\%) .{ }^{\star}$ and ${ }^{\star *}$ represented $p$ value significant at $<0.05$ and 0.01 level using Cochran's Q test and McNemar's test.

Table 5 shows the comparison in eating habits before and during the lockdown. Overall significant changes in the patterns of food consumption were observed in participants overtime. The percentage of participants who were always interested in healthy diet significantly decreased during the quarantine than before (37\% vs $33 \%$; $p<0.001)$. In parallel, there was a significant decrease in the percentage of participants who always consumed fast food during the quarantine ( $56 \%$ vs $52.9 \%$; $p=0.007)$. The percentage of participants who often consume snacks between meals increased during quarantine $(27.4 \%$ vs $29.4 \%, p<0.001)$. In contrast, the percentage of participants who never consumed fresh fruits and vegetables significantly increased during home quarantine ( $2.4 \%$ vs $3.7 \% ; p=0.019$ ).

\section{Discussion}

The present results of the study, while showing statistically significant changes in the physical and dietary behaviors before and during lockdown, represent a modest deviation in lifestyle in response to the lockdown imposed. Small but statistically significant changes in percentages are commonly observed in survey studies with large sample sizes, and these results should be interpreted with caution. The study nevertheless observed a negative effect of home quarantine on physical activity. Additionally, an unhealthy pattern of food consumption (the type of food, eating more frequently) was exhibited. Despite endorsements that home quarantine should not hinder people from practicing physical activity ${ }^{25}$, our results indicated that the opposite occurred for some respondents. The reported decrease in daily walking was a shift during quarantine, most likely due to the increased confinement time that people were required to follow, effectively increasing sedentary behavior and its associated risks ${ }^{26}$.

The present survey results agree with recent studies showing that lockdowns during a pandemic can adversely influence lifestyle activities worldwide, as well as participation in sports and physical activity ${ }^{27,28}$. Precautions during COVID-19 have decreased physical activity overall and availability of exercises. Despite the increased physical activity guidance and courses presented on social media ${ }^{29,30}$, the current results showed that it was not possible for participants with home activities to preserve their regular physical activity patterns adequately. It was previously demonstrated in China that different socio-economic factors and regional policies were linked to changes in physical activity ${ }^{31}$. Such influences should be considered while planning and endorsing physical activity interventions during COVID-19 pandemic. Recently, it was established that individuals exhibit a larger use (15\%) of data and communications technology during the quarantine period ${ }^{32}$. Hence, future physical activity intervention during pandemic can be based on communications technology solutions fitness apps to promote an active and healthy lifestyle during quarantine.

The present survey results also showed that contrary to the World Health Organization (WHO) guidance ${ }^{33,34}$, many people, but not all, responded by changing their eating behaviors, by greater consumption of snacks between meals. Regarding dietary behaviors, there seems to be no single behavioral problem. The negative changes in the majority of eating behaviors could be attributed to eating out of anxiety or boredom ${ }^{35}$, a dip in motivation to participate in physical activity or maintain healthy eating ${ }^{36}$ or an increase in mood-driven eating . $^{30}$. Alternative support for motivation during home quarantine may be sourced from assistive technologies such as apps, streaming services, and social media. In order to counteract poor dietary behaviors, meal planning and controlling food composition and meals' caloric content using information and communication technologybased solutions such as $m$ health and nutrition apps may be the best approach to combating unhealthy eating habits while in quarantine $\mathrm{s}^{32,35}$.

The present study results should be utilized for further research and development in public health campaign in the event of future lockdowns. During the COVID-19 pandemic restrictions, it was proposed that breaking up prolonged sitting by simple means, for instance 30 min periods of shifting between sitting and standing, can significantly increase the energy expenditure, consequently stimulating metabolic health in terms of glycemic control both in diseased and healthy people ${ }^{37,38}$. Individuals who have no history of eating disorders are encouraged to maintain healthy eating habits even during lockdowns by following these dietary behaviors: (a) reducing total number of meals, (b) good quality meals (e.g., more fresh vegetables, good quality protein source, avoiding refined and high glycemic foods), and (c) adopting intermittent or long fasting periods (i.e., more than $12 \mathrm{~h})^{29,32}$. Further research should address (i) insight into subpopulations for the development of interventions to address their needs, (ii) interference of diet and physical activity behaviors to improve interventions, and (iii) identification of conditions for successfully maintaining a healthy lifestyle before as well as during isolation. 
The authors acknowledge several limitations. The use of a self-reported questionnaire is subject to recall bias. Majority of the respondents answered the questionnaire during Ramadan, where fasting is mandatory for all able-bodied Muslims. This may have somehow influenced the responses of participants, though the questionnaire was made clear that it was entirely about the lockdown. Lastly and as mentioned previously, small changes in percentages can translate to statistically significant differences in large-scale studies and this should be considered whether such statistical difference have clinical implications.

\section{Conclusions}

The present survey results showed modest and acute adverse consequences of home quarantine as reflected by a more sedentary lifestyle and altered eating habits by some residents of Saudi Arabia. The present data support the development of recommendations for physical activity and nutrition to maintain healthy lifestyle during lockdowns utilizing social media platforms to develop health behavior support as well as identifying populations that are more likely to negatively respond to lockdowns by practicing unhealthy lifestyle behavior.

Received: 27 August 2020; Accepted: 1 March 2021

Published online: 15 March 2021

\section{References}

1. Grippo, A. J., Lamb, D. G., Carter, C. S. \& Porges, S. W. Social isolation disrupts autonomic regulation of the heart and influences negative affective behaviors. Biol. Psychiatr. 62, 1162-1170 (2007).

2. Loucks, E. B., Berkman, L. F., Gruenewald, T. L. \& Seeman, T. E. Relation of social integration to inflammatory marker concentrations in men and women 70 to 79 years. Am. J. Cardiol. 97, 1010-1016 (2006).

3. Mattioli, A. V. \& Ballerini, P. M. Lifestyle at time of COVID-19: how could quarantine affect cardiovascular risk. Am. J. Lifestyle Med. 14(3), 240-242. https://doi.org/10.1177/1559827620918808 (2020).

4. Al-Hazzaa, H. M. Physical inactivity in Saudi Arabia revisited: a systematic review of inactivity prevalence and perceived barriers to active living. Int. J. Health Sci. (Qassim). 12(6), 50-64 (2018).

5. Guthold, R., Stevens, G. A., Riley, L. M. \& Bull, F. C. Worldwide trends in insufficient physical activity from 2001 to 2016: a pooled analysis of 358 population-based surveys with 19 million participants. Lancet Glob. Health 6, e1077-e1086 (2018).

6. Fitbit, Inc. The Impact of Coronavirus on Global Activity (Online). https://blog.fitbit.com/covid-19-global-activity/. Accessed March 25th 2020.

7. Arries, E. J. \& Maposa, S. Cardiovascular risk factors among prisoners: an integrative review. J. Forensic. Nurs. 9, 52-64. https:// doi.org/10.1097/JFN.0b013e31827a59ef (2013).

8. Belavý, D. L. et al. Progressive adaptation in physical activity and neuromuscular performance during 520d quarantine. PLoS ONE 8, e60090. https://doi.org/10.1371/journal.pone.0060090 (2013).

9. Booth, F. W., Roberts, C. K. \& Laye, M. J. Lack of exercise is a major cause of chronic diseases. Compr. Physiol. https://doi. org/10.1002/cphy.c110025 (2012).

10. Sanchis-Gomar, F. et al. Physical inactivity and low fitness deserve more attention to alter cancer risk and prognosis. Cancer Prev. Res. (Phila) 8, 105-110 (2015).

11. Mattioli, A. V., Sciomer, S., Cocchi, C., Maffei, S. \& Gallina, S. Quarantine during COVID-19 outbreak: changes in diet and physical activity increase the risk of cardiovascular disease. Nutr. Metab. Cardiovasc. Dis. 30(9), 1409-1417. https://doi.org/10.1016/j. numecd.2020.05.020 (2020).

12. Torres, S. J. \& Nowson, C. A. Relationship between stress, eating behavior, and obesity. Nutrition 23(11-12), 887-94. https://doi. org/10.1016/j.nut.2007.08.008 (2007).

13. Biswas, A. et al. Sedentary time and its association with risk for disease incidence, mortality, and hospitalization in adults: a systematic review and meta-analysis. Ann. Intern. Med. 162, 123-132 (2015).

14. Johnson, R. K. et al. Dietary sugars intake and cardiovascular health: a scientific statement from the American Heart Association. Circulation 120, 1011-1020 (2009).

15. Vreman, R. A. et al. Health and economic benefits of reducing sugar intake in the USA, including effects via non-alcoholic fatty liver disease: a microsimulation model. BMJ Open 7, e013543 (2017).

16. Schiffman, S. S., Graham, B. G., Sattely-Miller, E. A. \& Peterson-Dancy, M. Elevated and sustained desire for sweet taste in africanamericans: a potential factor in the development of obesity. Nutrition 16, 886-893 (2000).

17. Bracale, R. \& Vaccaro, C. M. Changes in food choice following restrictive measures due to Covid-19. Nutr. Metab. Cardiovasc. Dis. 30, 1423-1426 (2020).

18. Torres, S. J. \& Nowson, C. A. Relationship between stress, eating behavior, and obesity. Nutrition 23, 887-894 (2007).

19. Laitinen, J., Ek, E. \& Sovio, U. Stress-related eating and drinking behavior and body mass index and predictors of this behavior. Prev. Med. (Baltim) 34, 29-39 (2002).

20. Alguwaihes, A. M. et al. Diabetes and Covid-19 among hospitalized patients in Saudi Arabia: a single-centre retrospective study. Cardiovasc. Diabetol. 19(1), 205. https://doi.org/10.1186/s12933-020-01184-4 (2020).

21. Sheshah, E. et al. Prevalence of diabetes, management and outcomes among Covid-19 adult patients admitted in a specialized tertiary hospital in Riyadh, Saudi Arabia. Diabetes Res. Clin. Pract. https://doi.org/10.1016/j.diabres.2020.108538 (2020).

22. Alfawaz, H., et al. Dietary intake and mental health among Saudi adults during COVID-19 lockdown. Int. J. Environ. Res. Public Health 18 (2021) [in-press].

23. Alfawaz, H. A. et al. Psychological well-being during COVID-19 lockdown: insights from a Saudi State University's Academic Community. J. King Saud. Univ. Sci. 33(1), 101262. https://doi.org/10.1016/j.jksus.2020.101262 (2021).

24. Dong, E., Du, H. \& Gardner, L. An interactive web-based dashboard to track COVID-19 in real time. Lancet Infect. Dis. 20, 533-534 (2020).

25. WHO. Physical Activity and Adults. Recommended Levels of Physical Activity for Adults Aged 18-64 Years. https://www.who.int/ dietphysicalactivity/factsheet_adults/en/. Accessed April 16th 2020.

26. Patterson, R. et al. Sedentary behaviour and risk of all-cause, cardiovascular and cancer mortality, and incident type 2 diabetes: a systematic review and dose response meta-analysis. Eur. J. Epidemiol. 33, 811-829. https://doi.org/10.1007/s10654-018-0380-1 (2018).

27. Ammar, A. et al. Effects of COVID-19 home quarantine on social participation and life satisfaction: preliminary results of the ECLB-COVID19 international online-survey. medRxiv https://doi.org/10.1101/2020.05.05.20091066 (2020).

28. Oliveira Neto, L. et al. \#TrainingInHome-training at home during the COVID-19 (SARS-COV2) pandemic: physical exercise and behavior-based approach. Rev. Bras. Fisiol. Exerc. 19, 4-14 (2020). 
29. Zhang, J. et al. Support or competition? How online social networks increase physical activity: a randomized controlled trial. Prev. Med. Rep. 8(4), 453-458. https://doi.org/10.1016/j.pmedr.2016.08.008 (2016).

30. Centola, D. Social media and the science of health behavior. Circulation 127(21), 2135-2144. https://doi.org/10.1161/CIRCU LATIONAHA.112.101816 (2013).

31. Hossain, M. M., Sultana, A. \& Purohit, N. Mental health outcomes of quarantine and isolation for infection prevention: a systematic umbrella review of the global evidence. SSRN Electron. J. https://doi.org/10.2139/ssrn.3561265 (2020).

32. Ammar, A. et al. Effects of home quarantine on mental health and lifestyle behaviours during the COVID-19 outbreak: insight from the "ECLB-COVID19" multi countries survey. medRxiv https://doi.org/10.1101/2020.05.04.20091017 (2020).

33. WHO. Food and Nutrition during Self-Quarantine: What to Choose and How to Eat Healthy; WHO: Geneva, Switzerland, 2020. http://www.euro.who.int/en/health-topics/diseaseprevention/nutrition/news/news/2020/3/food-and-nutrition-during-self-quara ntine-what-to-choose-andhow-to-eat-healthily. Accessed April 16th 2020.

34. WHO. http://www.euro.who.int/en/health-topics/health-emergencies/coronaviruscovid-19/novel-coronavirus-2019-ncov-techn ical-guidance/food-and-nutrition-tips-during-self-quarantine. Accessed April 16th 2020.

35. BDA. Eating Well During Coronavirus/COVID-19. https://www.bda.uk.com/resource/eating-well-during-coronavirus-covid-19. html. Accessed April 16th 2020.

36. Gardner, B. \& Rebar, A. L. Habit formation and behavior change. https://unimuenster.sciebo.de/apps/files/?dir=/2020_PROCa re4Life_3100050300/02_Online\%20survey\%20ECLBCOVID19\&fileid=1748656124\#pdfviewer. Accessed April 16th 2020.

37. Narici, M. et al. Impact of sedentarism due to the COVID-19 home quarantine on neuromuscular, cardiovascular and metabolic health: physiological and pathophysiological implications and recommendations for physical and nutritional countermeasures. Eur. J. Sport Sci. 12, 1-22 (2020).

38. Joy, L. Staying Active During COVID-19. 2020. https://www.exerciseismedicine.org/support_page.php/stories/?b=892. Accessed April 16th 2020.

\section{Acknowledgements}

The authors thank all the respondents of the study for their participation.

\section{Author contributions}

Study conception and design: H.A., N.M.A., A.A.A.; Study execution: H.A., N.J.A., D.A.A.; Data Collection: N.A.A., N.A.; Manuscript writing: O.E.A.; Statistical analysis: M.N.K.K., S.S.; Manuscript review: N.M.A., S.S., M.A.E., S.Y.A.

\section{Funding}

This study is supported by the Deputyship for Research and Innovation, Ministry of Education in Saudi Arabia, for funding this research work through project number IFKSURG-2020-102.

\section{Competing interests}

The authors declare no competing interests.

\section{Additional information}

Supplementary Information The online version contains supplementary material available at https://doi. org/10.1038/s41598-021-85330-2.

Correspondence and requests for materials should be addressed to N.M.A.-D.

Reprints and permissions information is available at www.nature.com/reprints.

Publisher's note Springer Nature remains neutral with regard to jurisdictional claims in published maps and institutional affiliations.

(c) (i) Open Access This article is licensed under a Creative Commons Attribution 4.0 International License, which permits use, sharing, adaptation, distribution and reproduction in any medium or format, as long as you give appropriate credit to the original author(s) and the source, provide a link to the Creative Commons licence, and indicate if changes were made. The images or other third party material in this article are included in the article's Creative Commons licence, unless indicated otherwise in a credit line to the material. If material is not included in the article's Creative Commons licence and your intended use is not permitted by statutory regulation or exceeds the permitted use, you will need to obtain permission directly from the copyright holder. To view a copy of this licence, visit http://creativecommons.org/licenses/by/4.0/.

(c) The Author(s) 2021 